\title{
Pseudomonas aeruginosa recognizes and responds aggressively to the presence of polymorphonuclear leukocytes
}

\begin{abstract}
Correspondence
Michael Givskov

mgivskov@sund.ku.dk
\end{abstract}

Received 9 June 2009

Revised 14 July 2009

Accepted 27 July 2009
Morten Alhede, ${ }^{1,2}$ Thomas Bjarnsholt, ${ }^{2,3}$ Peter $\varnothing$. Jensen, ${ }^{3}$ Richard Kerry Phipps, ${ }^{1}$ Claus Moser, ${ }^{3}$ Lars Christophersen, ${ }^{3}$ Louise Dahl Christensen, ${ }^{2}$ Maria van Gennip, ${ }^{2}$ Matt Parsek, ${ }^{4}$ Niels Høiby, ${ }^{3}$ Thomas Bovbjerg Rasmussen ${ }^{5}$ and Michael Givskov ${ }^{2}$

\author{
${ }^{1}$ Department of Systems Biology, Technical University of Denmark, DK-2800 Lyngby, Denmark \\ ${ }^{2}$ Department of International Health, Immunology and Microbiology, University of Copenhagen, \\ DK-2200 Copenhagen, Denmark \\ ${ }^{3}$ Department of Clinical Microbiology, Rigshospitalet, DK-2100 Copenhagen $\varnothing$, Denmark \\ ${ }^{4}$ University of Washington School of Medicine Seattle, Seattle, WA 98195-7242, USA \\ ${ }^{5}$ Department of Physiology, Chr. Hansen A/S, DK-2970 Hørsholm, Denmark
}

\begin{abstract}
Polymorphonuclear neutrophilic leukocytes (PMNs) play a central role in innate immunity, where they dominate the response to infections, in particular in the cystic fibrosis lung. PMNs are phagocytic cells that produce a wide range of antimicrobial agents aimed at killing invading bacteria. However, the opportunistic pathogen Pseudomonas aeruginosa can evade destruction by PMNs and thus cause persistent infections. In this study, we show that biofilm cells of $P$. aeruginosa recognize the presence of attracted PMNs and direct this information to their fellow bacteria through the quorum sensing (OS) signalling system. The bacteria respond to the presence of PMNs by upregulating synthesis of a number of QS-controlled virulence determinants including rhamnolipids, all of which are able to cripple and eliminate cells of the host defence. Our in vitro and in vivo analyses support a 'launch a shield' model by which rhamnolipids surround the biofilm bacteria and on contact eliminate incoming PMNs. Our data strengthen the view that cross-kingdom communication plays a key role in $P$. aeruginosa recognition and evasion of the host defence.
\end{abstract}

\section{INTRODUCTION}

Evading elimination by the host defence is a crucial virulence capacity of pathogens, enabling them to cause persistent infections, especially in immunocompromised patients (Kharazmi, 1991). Among known mechanisms are inhibition of the production of antimicrobial substances,

Abbreviations: $\mathrm{AHL}, \mathrm{N}$-acylhomoserine lactone; BAL, broncheoalveolar lavage; CF, cystic fibrosis; C4-HSL, N-butanoyl-L-homoserine lactone; 3oxo-C12-HSL, N-3-oxododecanoyl-L-homoserine lactone; DAPI, 4',6diamidino-2-phenylindole; LDH, lactate dehydrogenase; $\mathrm{Pl}$, propidium iodide; PMN, polymorphonuclear leukocyte; PNA FISH, peptide nucleic acid fluorescence in situ hybridization; POS, Pseudomonas quinolone signal; OS, quorum sensing.

The microarray data discussed in this publication have been deposited in NCBl's Gene Expression Omnibus (GEO, http://www.ncbi.nlm.nih.gov/ geo/) and are accessible through GEO Series accession number GSE6769.

Two supplementary tables are available with the online version of this paper. antimicrobial degradation, inhibition of the chemotaxis of polymorphonuclear neutrophilic leukocytes (PMNs) and induction of PMN apoptosis (Allen et al., 2005; Bortolussi et al., 1987; Kharazmi et al., 1984a, b). The biofilm lifestyle dominates in many chronic bacterial infections (Bjarnsholt et al., 2008; James et al., 2008; Saye, 2007; Yang et al., 2008). Biofilms consist of sessile aggregates of bacteria embedded in a self-made extracellular polymeric matrix. Important hallmarks of the biofilm mode of growth are tolerance to the highest deliverable doses of antibiotics (Donlan \& Costerton, 2002; Mah et al., 2003; Stewart \& Costerton, 2001) and resistance to the action of the host defence system (Bjarnsholt et al., 2005). It has been suggested that during colonization and subsequent formation of biofilms Pseudomonas aeruginosa keeps expression of virulence factors and other antigenic determinants at a minimum. This stealthy approach is carefully controlled by intercellular communication denoted quorum sensing (QS) (Fuqua et al., 1994). As the local cell density attains 
quorum size and biofilm areas expand, the production of secreted virulence factors escalates, which through a series of immune-activating events attracts PMNs. In vitro, PMNs are capable of penetrating and eliminating QS-deficient $P$. aeruginosa biofilms by phagocytosis but incapable of eliminating QS-proficient biofilms (Aaron et al., 2002; Bjarnsholt et al., 2005; Jesaitis et al., 2003). Instead of eliminating the bacteria, the PMNs are destroyed by the encounter with biofilm bacteria. It was reported previously that purified $P$. aeruginosa rhamnolipids could destroy PMNs by necrosis (Jensen et al., 2007). Like the majority of virulence factors, antibiotic tolerance and extracellular matrix DNA, rhamnolipid synthesis is delicately controlled by QS (Brint \& Ohman, 1995). We speculated that rhamnolipids might function as a protective mechanism and significantly contribute to the increased resistance of biofilms to phagocytic cells. Intriguingly, Morici et al. (2007) showed that AlgR represses rhamnolipid production in in vitro biofilms. These authors demonstrated that AlgR exerts its action directly on the rhlA promoter and that a $\triangle a \lg R$ biofilm produces increased amounts of rhamnolipids. Moreover, it was found that AlgR represses the RhlR-controlled QS cascade in biofilms, including the Pseudomonas quinolone signal (PQS) system (Morici et al., 2007). We therefore set out to investigate the mechanisms involved in biofilm-associated protection against attracted PMNs.

\section{METHODS}

Bacterial strains. The $P$. aeruginosa PAO1 wild-type used for the experiments was obtained from the Pseudomonas Genetic Stock Center (http://www.pseudomonas.med.ecu.edu, strain PAO0001). This PAO1 isolate has served as DNA source for the Pseudomonas Genome Project (http://www.pseudomonas.com) and, subsequently, as template for design of the Affymetrix P. aeruginosa GeneChip. The isogenic $\Delta$ lasR $\Delta r h l R$ QS mutant was constructed by Bjarnsholt et al. (2005).

The rhlA mutant, isogenic to the PAO1 wild-type, was obtained from the University of Washington, Seattle, WA, USA.

The $\Delta p q s A$ mutant was constructed by Aendekerk et al. (2005) and obtained from the laboratory of Paul Williams, University of Nottingham, Nottingham, UK.

Growth of biofilms. Biofilms were grown at $37{ }^{\circ} \mathrm{C}$ in continuousculture silicone tubing, as described by Hentzer et al. (2003, 2005), perfused with ABT minimal medium supplemented with $0.5 \%(\mathrm{w} / \mathrm{v})$ glucose (Clark \& Maaløe, 1967; Pamp \& Tolker-Nielsen, 2007). The medium was supplemented with antibiotics where appropriate. Unless otherwise stated, all strains were incubated in growth medium at $37^{\circ} \mathrm{C}$. Due to the need for a large quantity of cells for the transcriptomic analysis, biofilms were grown in a $12 \mathrm{~cm}$ long silicone flow tube (inner diameter $0.8 \mathrm{~cm}$, total volume $6 \mathrm{ml}$ ) instead of traditional flow channels. The flow tubes were connected to a medium reservoir with silicone tubing of smaller dimension, with the inclusion of a peristaltic pump creating the liquid flow. A bubble trap was included between the flow tube and the pump, and the effluent was collected in a waste flask that was connected via silicone tubing to the distal end of the flow tube. Overnight cultures of PAO1 wild-type or the $\Delta$ lasR $\Delta r h l R$ mutant were diluted 100 -fold and $6 \mathrm{ml}$ was injected into each channel. To allow cell attachment the flow into the tube was halted for $1 \mathrm{~h}$, by clamping both the influent and effluent tubes. The medium flow was set to 23 r.p.m. $\left(60 \mathrm{ml} \mathrm{h}^{-1}\right)$ using a Watson Marlow $205 \mathrm{~S}$ pump. The relatively high flow rate was maintained to ensure that planktonic bacteria were washed out of the set-up.

PMN treatment of biofilms. The biofilms were allowed to grow and develop in the biofilm flow tubes for 3 days before challenge with PMNs. Fresh PMNs from human volunteers were isolated as described by Bjarnsholt et al. (2005). Prior to PMN injection the flow was halted. Ten million PMNs were resuspended in $6 \mathrm{ml} \mathrm{Krebs-}$ Ringer buffer supplemented with $10 \mathrm{mM}$ glucose and injected into the flow tubes. The concentration of PMNs was found by microscopy to be approximately 1 PMN per 1000 bacterial cells. PMNs and biofilm were incubated for $2 \mathrm{~h}$. After incubation the fluid inside the tube was gently collected and the attached biofilm cells were mechanically removed and collected in either $6 \mathrm{ml}$ RNAlater (Ambion) for transcriptome analysis or $200 \mu$ l ethyl acetate for rhamnolipid detection.

Dynorphin A treatment of biofilms. The biofilms were allowed to grow and develop in the biofilm flow tubes for 3 days before challenge with $100 \mu \mathrm{M}$ dynorphin A (1-17). Prior to dynorphin A injection the flow was halted. Dynorphin A (1-17) (AnaSpec) was resuspended in $6 \mathrm{ml}$ Krebs-Ringer buffer, supplemented with $10 \mathrm{mM}$ glucose, to a final concentration of $100 \mu \mathrm{M}$ and injected into the flow tubes. Dynorphin A and biofilm were incubated for $30 \mathrm{~min}$ or $2 \mathrm{~h}$. After incubation the fluid inside the tube was gently collected and the attached biofilm cells were mechanically removed and collected in either $6 \mathrm{ml}$ RNAlater for transcriptome analysis or $200 \mu \mathrm{l}$ ethyl acetate for rhamnolipid detection.

Quantification of rhamnolipid. The biofilm was collected in $200 \mu \mathrm{l}$ ethyl acetate and sonicated following evaporation. The biomass was redissolved in methanol for mass spectrometry analysis.

A standard curve for rhamnolipid B [concentration vs total ionization current (TIC)] was calculated from LC-ESI-MS data. To minimize potential differences in ionization levels of rhamnolipid between the samples the rhamnolipid standards used for calculating the concentration curve were analysed immediately prior to, as well as after the samples undergoing analysis. The TIC level was determined on the $\left[\mathrm{M}+\mathrm{NH}_{4}\right]^{+} 247$ ion at 668.4, over the $7 \mathrm{~s}$ during which rhamnolipid B was eluted.

HPLC-MS analysis was performed with an Agilent 1100 series HPLC connected to a micromass LCT oaTOF MS. The concentration of rhamnolipid in untreated culture was set as index 100 .

In the analysis the total rhamnolipid concentration was derived from the six major rhamnolipids, with the following masses $\left[\mathrm{M}+\mathrm{NH}_{4}\right]^{+}$: $668.4,694.4,696.4,522.4,548.4$ and 550.4. These correspond to C10C10-Rha-Rha, an unidentified C10-C12 $\Delta$-Rha-Rha, C10-C12-Rha$\mathrm{Rha}$, and the respective monorhamnose derivatives.

Genechip microarray analysis of biofilms. The RNAlatersuspended biofilm cells were sonicated three times for $10 \mathrm{~s}$ to disperse clumps from the biofilm. Four times $2 \mathrm{ml}$ of RNAlatersuspended cells were pelleted and subsequently lysed with $100 \mu \mathrm{l}$ of $1 \mathrm{mg}$ lysozyme $\mathrm{ml}^{-1}$ at room temperature for $13 \mathrm{~min}$. Total RNA was isolated with RNeasy Mini kits (Qiagen) and contaminating chromosomal DNA was removed by RQ1 RNase-free DNase treatment. cDNA was synthesized from $12 \mu \mathrm{g}$ total RNA in $1 \times$ first-strand buffer containing $100 \mathrm{ng} \mu^{-1}$ random primers (Invitrogen Life Technologies), $10 \mathrm{mM}$ DTT, $0.5 \mathrm{mM}$ dNTPs, $0.5 \mathrm{U}$ $\mu 1^{-1}$ SUPERase In (Ambion) and $25 \mathrm{U} \quad \mu \mathrm{l}^{-1}$ SuperScriptIII (Invitrogen Life Technologies). After cDNA synthesis, RNA was removed by $1 \mathrm{M} \mathrm{NaOH}$ at $65{ }^{\circ} \mathrm{C}$ for $30 \mathrm{~min}$ and the reaction was 
neutralized with $1 \mathrm{M} \mathrm{HCl}$. Four micrograms of cDNA was fragmented with $0.8 \mathrm{U}$ DNase I (Amershan Pharmacia Biotech) in $1 \times$ OnePhorAll Buffer (Amershan Pharmacia Biotech). Terminal labelling of fragmented cDNA was done using the Enzo BioArray Terminal Labelling kit with Biotin-ddUTP (Enzo Diagnostics). Biotinylated cDNA was hybridized to a GeneChip P. aeruginosa Genome Array and scanned according to standard GeneChip protocols (Affymetrix). The wild-type PMN exposure was performed as three individual experiments [once in the Parsek lab (PMN donor Rasmussen) and twice in the Givskov lab (PMN donor Alhede)]. The $\triangle l a s R \Delta r h l R$ mutant PMN exposure experiment was performed as two individual experiments. The transcriptome analysis was performed with ArrayStar software (DNASTAR). Performing a $t$-test on the dataset, genes were recorded as being (significantly) differentially expressed if the absolute value of the fold change was $\geqslant 3$ and the $P$ value was $\leqslant 0.05$. The relaxed fold change criterion was chosen because of the assumed heterogeneous nature of biofilm. It is likely that subpopulations of bacteria within the biofilm have gene expression patterns substantially different from those of the bulk of the cells in the biofilm. Inherent to the harvesting method and the microarray technique, gene expression patterns in such subpopulations will be averaged with the bulk population in the analysis. In order to allow such subpopulation gene expression patterns to be recorded in the analysis we chose a less stringent cut-off value.

Real-time PCR analysis. Quantitative real-time PCR was used for validation of the microarray results.

Primer design. Primers (see Supplementary Table S1, available with the online version of this paper) for each gene in the real-time PCRs were designed using Integrated DNA Technologies Primer Quest software (http://www.idtdna.com). Briefly, the amplicon sizes ranged from 80 to $200 \mathrm{bp}$ and the primer melting temperatures were designed for $60{ }^{\circ} \mathrm{C}$, with a melting temperature difference of less than $2{ }^{\circ} \mathrm{C}$ for each primer pair. The primer sequences were also subjected to BLAST analysis against the $P$. aeruginosa PAO1 genome to eliminate the possibility of non-specific binding.

Real-time PCR. Each real-time PCR mixture (final volume, $20 \mu \mathrm{l}$ ) contained $9 \mu \mathrm{l}$ cDNA, $10 \mu \mathrm{l}$ SYBR Green qPCR Master Mix 2x (Fermentas) and $500 \mathrm{nM}$ of each forward and reverse primer. Realtime PCR was performed with a chromo4 (MJ Research) using the following cycling parameters: initial denaturation at $95{ }^{\circ} \mathrm{C}$ for $10 \mathrm{~min}$ followed by 40 cycles of $95{ }^{\circ} \mathrm{C}$ for $15 \mathrm{~s}, 60{ }^{\circ} \mathrm{C}$ for $30 \mathrm{~s}$ and $72{ }^{\circ} \mathrm{C}$ for $30 \mathrm{~s}$.

The data were analysed using the efficiency-corrected relative quantification method (Pfaffl, 2001). To ensure correctness of the quantification we normalized the expression of the target genes to the reference gene $r p o D$, whose expression was found to be stable in the DNA microarray analysis. Furthermore this gene was found by Savli et al. (2003) to possess the most stable expression of housekeeping genes. To control for variations between runs, the housekeeping gene and the various target genes for each individual treatment were amplified at the same time on a 96-well plate. Fold changes in expression of target genes in the treated samples were calculated relative to the average level of the respective gene in the non-treated sample.

To allow accurate analysis we decided that the PCR efficiency of each gene (including housekeeping genes) was within $5 \%$ from the treated condition to the non-treated. Accordingly, the average efficiencies of each gene in this study were very similar for the conditions compared, allowing accurate analysis.

PMN killing in biofilm. To monitor the effect of biofilms on PMNs, the biofilms including PMNs were harvested and resuspended in $200 \mu \mathrm{l}$ PBS, vortexed and gently centrifuged followed by sterile filtering $(0.22 \mu \mathrm{m})$. Then the lactate dehydrogenase (LDH) activity was measured using a Cytotoxity Detection kit (Roche). LDH is a stable cytoplasmic enzyme present in all cells, which is rapidly released into the cell culture supernatant upon damage of the plasma membrane (Weyermann et al., 2005). Two hundred microlitres of reaction mixture was added to $200 \mu \mathrm{l}$ supernatant and incubated for $30 \mathrm{~min}$ at room temperature. The absorbance was measured at $490 \mathrm{~nm}$ and $590 \mathrm{~nm}$. High, low and negative controls were included in all experiments: high, biofilm including PMNs harvested in $1 \%$ Triton; low, non-exposed PMNs only; negative, water. The number of dead PMNs was calculated as a percentage relative to the high control.

The above method was verified once by FACS analysis. The biofilms including PMNs were harvested and resuspended in $400 \mu \mathrm{l}$ PBS and stained with $5 \mu \mathrm{l}$ FITC-conjugated CD15 antibody (Becton Dickinson). Next, $1 \mu \mathrm{l}$ of $20 \mathrm{mM}$ propidium iodide (PI) (P-4170 Sigma) was added to monitor integrity of the cells and release of DNA. This staining enabled us to quantify the dead PMNs by FACS. Fluorescence intensity of the samples was measured on a FACS Calibur (Becton Dickinson) using cellquest software.

Lung infection of BALB/c mice by intratracheal instillation of alginate-embedded $\boldsymbol{P}$. aeruginosa. Female $\mathrm{BALB} / \mathrm{c}$ mice were purchased from M\&B Laboratory Animals at 10-11 weeks of age. The mice were of equal size, and were maintained on standard mouse chow and water ad libitum for a minimum of 1 week prior to challenge. The National Animal Ethics Committee, Denmark, authorized all animal experiments. The mouse experiments were performed as described by Pedersen et al. (1990).

Bacteriology in broncheoalveolar lavage (BAL) fluid. Exposed tracheas of anaesthetized mice were cannulated with a 22 gauge catheter (OPTIVA* 2; Johnson \& Johnson Medical). BAL was performed by flushing five times with $1.5 \mathrm{ml}$ ice-cold PBS without $\mathrm{Ca}^{2+}$ and $\mathrm{Mg}^{2+}$. The BAL fluid was stored on ice until staining for necrotic PMNs. The mean recovery of BAL fluid was $1.1 \mathrm{ml}(\mathrm{CV}$ $13 \%)$.

Quantitative lung bacteriology. For colony counting, the exposed lungs were isolated in $5 \mathrm{ml} 0.9 \% \mathrm{NaCl}$, and homogenized on ice. A serial dilution of the lung homogenate mixed with BAL fluid was performed, and dilutions were plated on blue agar plates (State Serum Institute, Copenhagen, DK), which are selective for Gram-negative bacilli (Høiby, 1974).

Necrotic and apoptotic PMNs in mouse BAL fluid. PMNs were stained with an Annexin V-FITC Apoptosis Detection kit I (556747, BD Biosciences Pharmingen), using a modification of the preparation supplied by the manufacturer. Two hundred microlitres of BAL fluid was equilibrated by centrifugation with $2.5 \mathrm{ml}$ cold $1 \times$ binding buffer (BD Biosciences Pharmingen) at $350 \mathrm{~g}$ for $7 \mathrm{~min}$ at $5{ }^{\circ} \mathrm{C}$. For discrimination between necrotic and apoptotic PMNs, the pellet was mixed with $100 \mu \mathrm{l} 1 \times$ binding buffer with $2.5 \mu \mathrm{g} \mathrm{PI} \mathrm{ml}{ }^{-1}$, annexin V-FITC component (1:40), and the PMN phenotypic surface marker monoclonal allophycocyanin (APC)-conjugated rat anti-Ly-6G antibody (clone RB6-8C5, BD Biosciences Pharmingen) (1:50) and incubated for $15 \mathrm{~min}$ at room temperature in the dark. The incubation was terminated by addition of $400 \mu \mathrm{l} 1 \times$ binding buffer and the samples were analysed by flow cytometry.

PNA FISH. Deparaffinized tissue sections were analysed by fluorescence in situ hybridization (FISH) using peptide nucleic acid (PNA) probe (Stender, 2003). A mixture of Texas-red-labelled $P$. aeruginosa-specific PNA probe, a fluorescein-labelled Staphylococcus aureus-specific PNA probe and a fluorescein-labelled or Texas-redlabelled universal bacterium PNA probe in hybridization solution (AdvanDx) was added to each section and hybridized in a PNA FISH 
workstation at $55{ }^{\circ} \mathrm{C}$ for $90 \mathrm{~min}$ covered by a lid. The slides were washed for $30 \mathrm{~min}$ at $55{ }^{\circ} \mathrm{C}$ in Wash Solution (AdvanDx), mounting medium with 4',6-diamidino-2-phenylindole (DAPI) was applied, and a coverslip was added to each slide. The entire PNA FISH procedure took approximately $2.5 \mathrm{~h}$. Slides were read using a fluorescence microscope equipped with an FITC, a Texas red, a dual FITC/Texas red and a DAPI filter.

\section{RESULTS}

To investigate the importance of rhamnolipid production for PMN viability in vivo, we infected lungs of mice with equal amounts of rhamnolipid-proficient (PAO1 wildtype) and -deficient (rhlA mutant) P. aeruginosa strains. Our alginate bead model of infection features introduction of bacteria in the form of aggregates, and previous microscopic investigations have revealed that the bacteria organize in biofilm aggregates surrounded by multiple PMNs similar to those in the lungs of cystic fibrosis (CF) patients and chronic infected wounds ( $\mathrm{Wu}$ et al., 2000). After $24 \mathrm{~h}$, flow-cytometry-based live-dead stain analysis (see Methods) showed that the BAL fluid obtained from the group of mice infected with the rhlA mutant contained twofold more viable PMNs $(P<0.0001, t$-test $)$ compared with the PAO1 wild-type-infected group (Fig. 1a). Overnight, we also found one order of magnitude higher numbers of c.f.u. in the lungs of wild-type-infected mice compared with a two orders of magnitude reduction in those infected with the rhlA mutant $(P<0.0001$, MannWhitney test) (Fig. 1b). PMNs are summoned to the lungs upon infection and have a high turnover rate. However, with respect to wild-type bacteria, the present $24 \mathrm{~h}$ 'snapshot' measurements suggest that rhamnolipid production (Fig. 1c) may account for the elimination of a significantly higher fraction of the attracted PMNs in contrast to the rhlA-deficient bacteria, which become eliminated by the action of the PMNs. This view was strengthened by in vitro studies of biofilms in flow tubes. Measurement of the LDH activity of in vitro biofilms exposed to freshly isolated PMNs revealed that a large fraction of the PMNs exposed to the PAO1 wild-type biofilm lysed during the period of the experiment, whereas no PMNs lysed after exposure to the rhlA mutant (Fig. 2c).

In line with Morici et al. (2007), we were only able to detect very low amounts of rhamnolipid in the in vitro biofilm of $P$. aeruginosa. We then hypothesized that the rhamnolipid content might rise and spike in the biofilm under conditions of PMN exposure. In order to prove this hypothesis, we measured the amount of rhamnolipids after $2 \mathrm{~h}$ of exposure to freshly isolated PMNs. Interestingly, when comparing with non-exposed biofilms, we found a significant increase in rhamnolipid concentration $(P<0.003, t$-test $)$ in the cell fraction of the harvested biofilms (Fig. 2a). As expected, we did not find any detectable amounts of rhamnolipids in the rhlA-deficient strain before or after exposure to the PMNs (Fig. 2a). In addition, we found a more than 2000-fold higher rhamnolipid concentration in the biofilm cell paste than
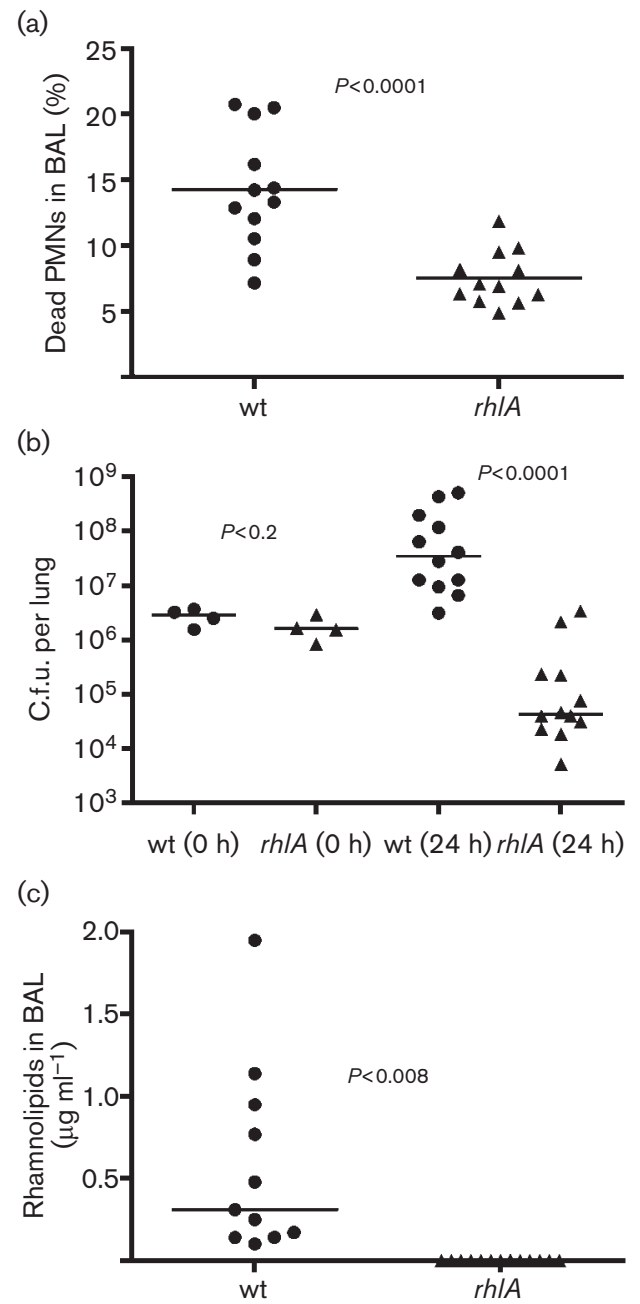

Fig. 1. Intratracheal instillation of alginate-embedded $P$. aeruginosa in BALB/c mice. (a) After $24 \mathrm{~h}$ of infection there is a significant higher proportion of dead $\mathrm{PMNs}$ in the BAL fluid of $\mathrm{BALB} / \mathrm{c}$ mice infected with the PAO1 wild-type infected mice ( $)$ compared to the corresponding $r h / A$ mutant-infected mice $(\mathbf{A})$. The horizontal bars represent mean percentage dead PMNs. Each group contained 12 mice at the day of sacrifice $(P<0.0001, t-$ test). (b) There is a significant difference $(P<0.0001$, MannWhitney test) in bacteriology after $24 \mathrm{~h}$ in the lungs of mice infected with PAO1 wild-type and the corresponding rhlA mutant (A). Immediately after infection four mice were sacrificed to estimate the inoculum size (at $\mathrm{Oh}$ ). The horizontal bars represent median c.f.u. numbers. (c) Rhamnolipid concentration in BAL fluid from mice infected with PAO1 wild-type $(\bullet)$ and the corresponding $r$ h/A mutant $(\boldsymbol{\Delta})$. The horizontal bars represent median rhamnolipid concentration.

in the surrounding fluid $(P<0.0001, t$-test $)$, showing that the de novo-synthesized rhamnolipids stick to the biomass rather than being released to the fluid (Fig. 2b). We therefore propose that PMNs become eliminated by contact with the biofilm aggregates, in accordance with our observations that microscopic inspections cannot 

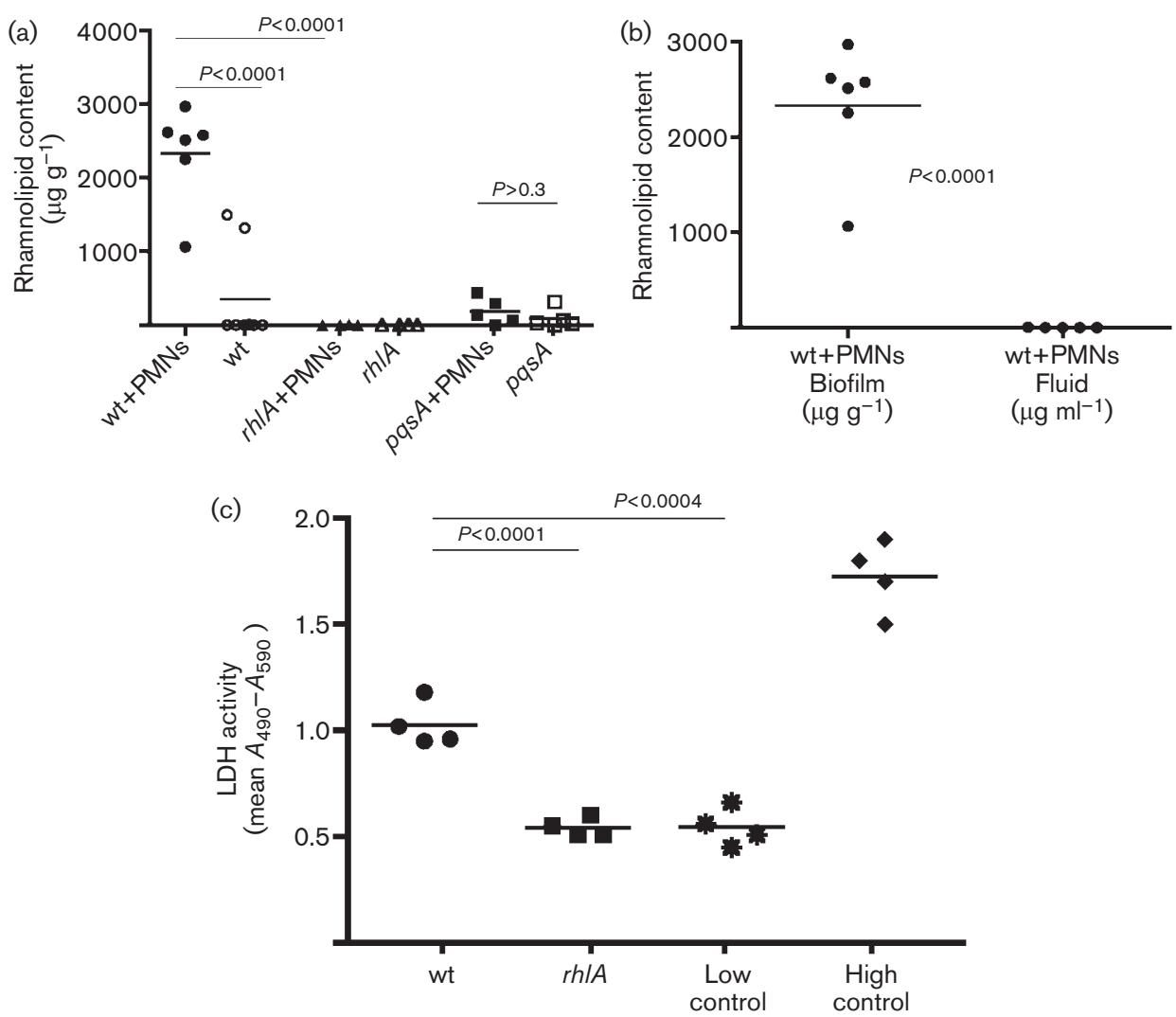

Fig. 2. Rhamnolipid measurement and LDH activity in in vitro biofilm. Rhamnolipids produced in the flow-tube biofilms were measured by mass spectrometry. (a) Rhamnolipid contained by the biofilm cells in the presence (solid symbols) and absence (empty symbols) of PMNs. $n=6$. (b) Comparison of rhamnolipid in the biofilm cell paste and in the fluid surrounding the biofilm. $n=6$. (c) As a marker of PMN integrity, we measured the lactate dehydrogenase (LDH) activity of the PAO1 wild-type biofilm $(\bullet)$ and the corresponding rhamnolipid mutant $(r h / A)(\boldsymbol{\square})$. Increased levels of LDH activity indicate PMN necrosis. $\bullet$, High necrosis level (high control) was measured after $1 \%$ Triton treatment of PMNs. ${ }^{*}$, Low control was measured in flow tube incubated with PMNs in the absence of bacteria. $n=4$. Horizontal bars represent mean values and significance was calculated by $t$-test.

demonstrate the presence of intact PMNs in close contact with the top layers of the in vitro biofilms (Fig. 3c).

Numerous microscopic investigations of $P$. aeruginosainfected ex vivo tissue samples from the lungs of CF patients and chronic wounds (Fig. 3a, b) gave the impression that PMNs may gather in the periphery but never reach inside the biofilm cell aggregates. Furthermore, the biofilm aggregates are surrounded by blue-stained smears, which may represent DNA leaking out of nearby, lysed PMNs. Biofilm-associated rhamnolipids therefore appear to be a feasible explanation for biofilm resistance to the cellular immune defence.

Taken together, the present study suggests that the biofilm bacteria can sense the presence of PMNs and respond accordingly. Consequently, we should be able to see changes in the transcriptomic profile of the exposed bacteria in vitro. By means of Affymetrix GeneChips we calculated absolute expression values obtained from PMNexposed biofilms compared to the corresponding values of a non-exposed control. The changes in gene expression were calculated as simple fold changes. In line with our rhamnolipid measurements, we found that among 27 other genes there was a significant $(P<0.03$ and $P<0.01)$ upregulation of the rhlA and $r h l B$ genes during PMN exposure (Table 1), with very low expression under conditions of no exposure. We validated the change in transcription of rhlA, pqsA and $r p o D$ found by the GeneChips by RT-PCR and obtained comparable results (See Supplementary Table S2).

Rhamnolipid-dependent PMN killing appears to be QS regulated (Jensen et al., 2007). When comparing with data presented by Hentzer et al. (2003) and Rasmussen et al. (2005), $85 \%$ of the PMN-responsive genes are also regulated by QS. In particular, those virulence factors encoded by $p h z, \operatorname{rhl} A B$ and $\operatorname{lec} B$ are able to cripple and eliminate eukaryotic cells (Allen et al., 2005; Jensen et al., 2007; Sonawane et al., 2006). These genes have been shown to be controlled by the PQS branch of the QS system 

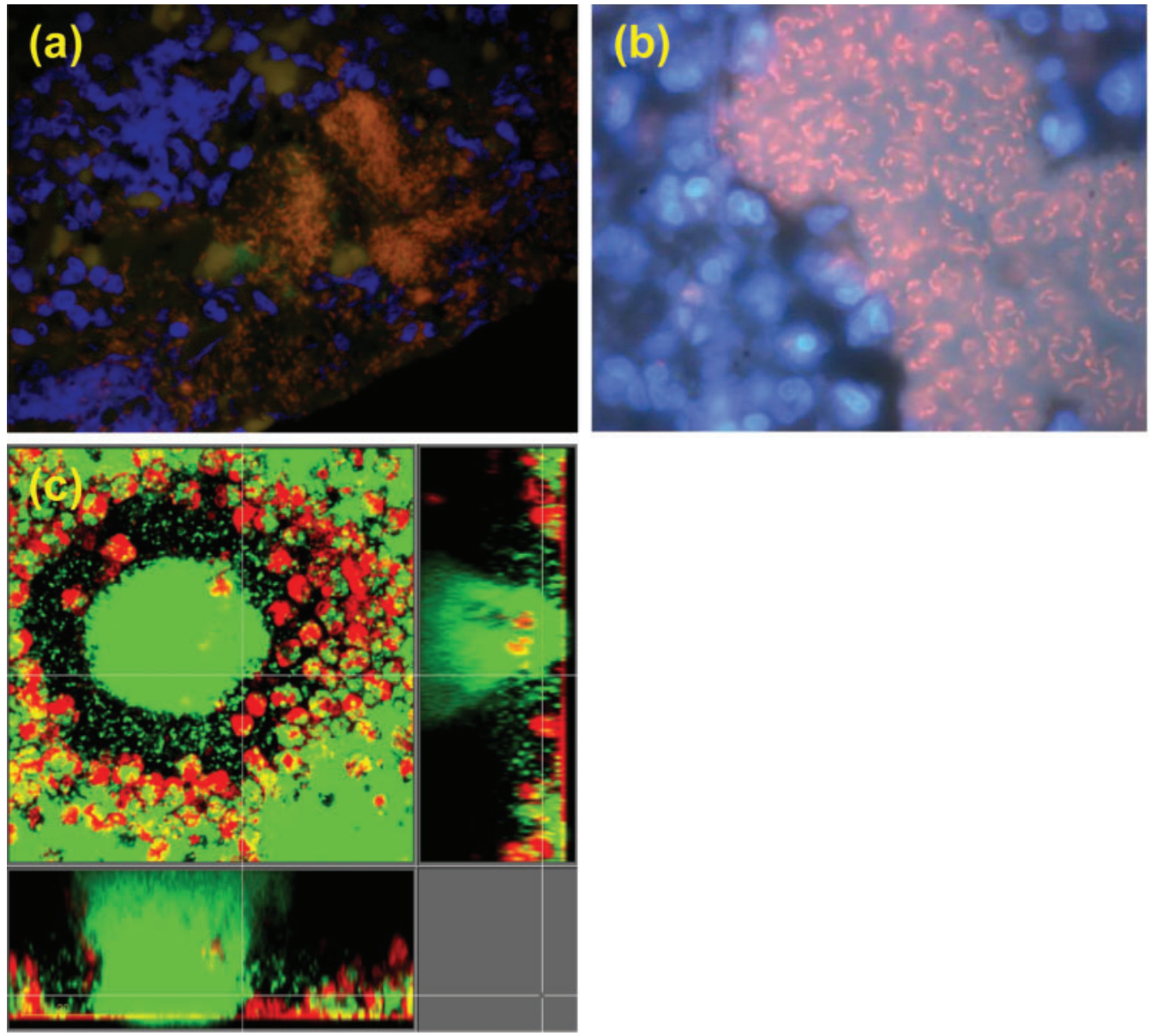

Fig. 3. Microscopy of sections from (a) a chronic $P$. aeruginosa-infected wound (b) and a chronic $P$. aeruginosa-infected CF lung, showing a sharp interface between biofilm aggregates and immune cells. This interface is also found in PMN-overlaid in vitro biofilm (c). (a, b) P. aeruginosa (red) are stained with specific PNA FISH and PMNs are stained (blue) with DAPI. The pictures were obtained using an Olympus fluorescence microscope. (c) $P$. aeruginosa are tagged with GFP and PMNs are stained (red) with CYTO62; the pictures were obtained using a Leica TCS-SP5 confocal laser scanning microscope (Leica Microsystems) equipped with an argon laser and helium-neon laser for excitation of the fluorophores. Magnification: $\times 1000(a, b) ; \times 400(c)$.

(Diggle et al., 2003; Wade et al., 2005). The biosynthetic pqs operon is also upregulated during PMN exposure, suggesting an increase in PQS signal production. Concurrently, we found in the biofilm set-up that the $p q s A$ mutant is unable to respond by increasing rhamnolipid production upon exposure to PMNs (Fig. 2a). The PQS signal is known to stimulate the RhlR-C4-HSLcontrolled lower part of the QS hierarchy through PqsR and PqsE. It is therefore likely that the cells in a $P$. aeruginosa biofilm channel the PMN response by means of the PQS branch of the QS system. In support of this is the finding that a QS-deficient $(\Delta l a s R \Delta r h l R)$ biofilm showed a completely different response, i.e. no upregulation of QScontrolled genes and virulence factors (Table 1).

Comparison with a previous analysis showed that $70 \%$ (19 of 27) of the present PMN-upregulated genes were also upregulated in a $\triangle a \lg R$ mutant biofilm studied by Morici et al. (2007) (genes also upregulated in a $\Delta a l g R$ mutant biofilm are indicated in Table 1). Since AlgR is known to repress the PQS-controlled genes in biofilms, it is tempting to speculate that a cue from the PMNs overrides AlgR repression and thereby induces the observed virulent response. Evidence has been provided by Zaborina et al. (2007) that the opioid and endogenous $\kappa$-agonist dynorphin A induces production of PQS and phenazines and this induction requires functional QS systems. The group demonstrated that $100 \mu \mathrm{M}$ dynorphin $\mathrm{A}(1-17)$ is required to enhance the production of virulence factors in a planktonic P. aeruginosa culture (Zaborina et al., 2007). Since immune cells are capable of synthesis and release of opioids at sites of inflammation (Cabot et al., 2001; Chadzinska et al., 2005; Przewlocki et al., 1992) it is an appealing hypothesis that these peptides are in fact the signals by which $P$. aeruginosa biofilms recognize the presence of incoming and attacking PMNs. 
Table 1. GeneChip transcriptomic analysis of 3-day-old in vitro $P$. aeruginosa biofilms exposed to PMNs for $2 \mathrm{~h}$

By comparison with unexposed biofilms, we found that 28 genes were significantly $(P<0.05 \quad t$-test and 3 -fold changed $)$ differentially expressed. Results are based on the mean of three separate experiments. Of these differentially regulated genes, $85 \%$ are QS controlled according to Hentzer et al. (2003); these QS-controlled genes are identified in the 'QS controlled' column. Genes found to be AlgR repressed in biofilms by Morici et al. (2007) are indicated in the 'AlgR repressed' column. We also included a QS-deficient $\Delta r h l \Delta R l a s R$ biofilm in the transcriptome analysis. The response to PMN exposure was completely different from that of the isogenic QS-proficient strain, with only two genes being significantly upregulated.

\begin{tabular}{|c|c|c|c|c|}
\hline $\begin{array}{l}\text { Probe } \\
\text { set ID }\end{array}$ & Gene & $\begin{array}{c}\text { Fold } \\
\text { change }\end{array}$ & $\begin{array}{c}\text { QS } \\
\text { controlled }\end{array}$ & $\begin{array}{c}\text { AlgR } \\
\text { repressed }\end{array}$ \\
\hline \multicolumn{5}{|l|}{ PAO1 } \\
\hline PA0263 & $h c p C$ & 3.5 up & No & Yes \\
\hline PA0263 & $h c p C$ & 3.5 up & No & Yes \\
\hline PA0996 & $p q s A$ & 3.6 up & Yes & Yes \\
\hline PA0997 & $p q s B$ & 8.2 up & Yes & Yes \\
\hline PA0998 & $p q s C$ & 4.8 up & Yes & Yes \\
\hline PA0999 & $p q s D$ & 4.3 up & Yes & Yes \\
\hline PA1000 & pqsE & 3.9 up & Yes & Yes \\
\hline PA1001 & phnA & 4.4 up & Yes & Yes \\
\hline PA1178 & oprH & 3.3 up & No & No \\
\hline PA1901 & $p h z C 2$ & 7.6 up & Yes & Yes \\
\hline PA1902 & phzD2 & 6.2 up & Yes & Yes \\
\hline PA1903 & phzE2 & 8.4 up & Yes & Yes \\
\hline PA1904 & $p h z F 2$ & 8.1 up & Yes & Yes \\
\hline PA1905 & $p h z G 2$ & 11.5 up & Yes & Yes \\
\hline PA2069 & & 4.3 up & Yes & Yes \\
\hline PA3189 & & 3.0 down & No & No \\
\hline PA3361 & $\operatorname{lec} B$ & 8.2 up & Yes & Yes \\
\hline PA3478 & $r h l B$ & 5.9 up & Yes & Yes \\
\hline PA3479 & rhlA & $6.1 \mathrm{up}$ & Yes & Yes \\
\hline PA3520 & & 3.0 up & Yes & No \\
\hline PA4104 & & 3.0 up & No & No \\
\hline PA4129 & & 3.7 up & Yes & No \\
\hline PA4130 & & 3.9 up & Yes & No \\
\hline PA4131 & & 4.2 up & Yes & No \\
\hline PA4141 & & 7.3 up & Yes & Yes \\
\hline PA4209 & phzM & 3.0 up & Yes & No \\
\hline PA4210 & phzA1 & 3.0 up & Yes & Yes \\
\hline PA4211 & phzB1 & 14.4 up & Yes & Yes \\
\hline PA4217 & $p h z S$ & 8.8 up & Yes & No \\
\hline \multicolumn{5}{|c|}{$\Delta r h l R \Delta l a s R$} \\
\hline PA3406 & hasD & 3.3 up & No & No \\
\hline PA4770 & $l l d P$ & 3.6 up & No & No \\
\hline
\end{tabular}

We decided to challenge this hypothesis by exposing a 3day-old biofilm to $100 \mu \mathrm{M}$ dynorphin A (1-17) for $30 \mathrm{~min}$ or $120 \mathrm{~min}$. After exposure we measured the rhamnolipid concentration in the biofilm as previously described. In comparison to the non-treated biofilm no induction of rhamnolipid was observed (Fig. 4). Microarray analysis of the harvested biofilms revealed 225 and 13 genes,

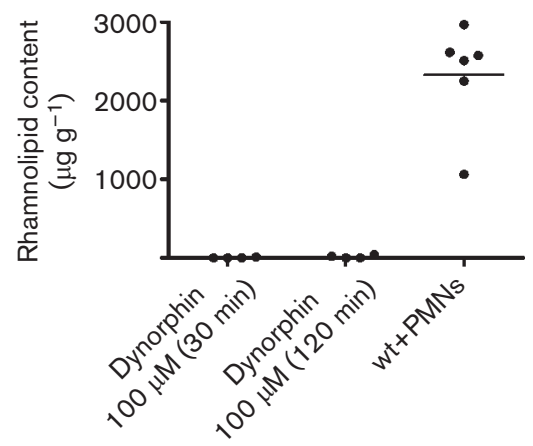

Fig. 4. Rhamnolipid content of in vitro biofilm exposed to $100 \mu \mathrm{M}$ dynorphin for $30 \mathrm{~min}$ or $120 \mathrm{~min}$. Rhamnolipids produced in the flow-tube biofilms were measured by mass spectrometry. Treatment with $100 \mu \mathrm{M}$ dynorphin was not found to induce any rhamnolipid production in the biofilm set-up. $n=4$ in each group.

respectively, being differentially ( $>3$-fold) regulated following $30 \mathrm{~min}$ and $120 \mathrm{~min}$ of dynorphin exposure. Consistent with the rhamnolipid measurement, we were unable to detect any induction of PQS-controlled transcription, including the $r h l A B$ genes. These data indicate that dynorphin $\mathrm{A}$ is not the cue from the PMNs that activates the PQS system and makes the bacteria launch the protective shield.

\section{DISCUSSION}

P. aeruginosa uses QS communication systems to trigger the onset of virulence factor production. The production of virulence factors contributes to activation of the immune system and PMNs will be summoned to the sites of infection. In the present study we show that the presence of PMNs triggers the $P$. aeruginosa biofilm to respond aggressively by producing a QS-dependent cocktail of toxic components rather than protective mechanisms such as those involved in oxidative stress (Chang et al., 2005; Small et al., 2007). This corroborates the previous finding that freshly isolated PMNs are unable to develop an oxidative burst and phagocytose in vitro $P$. aeruginosa biofilm (Bjarnsholt et al., 2005).

Among the upregulated substances are rhamnolipids, which stick to the biofilm, forming a deadly shield surrounding the biofilm cells. Approaching PMNs are consequently killed by contact and the bacteria persist. This is further supported by the results of Kownatzki et al. (1987), who found that sputum from $P$. aeruginosainfected CF patients contained rhamnolipid and correlated high concentrations with poor clinical state.

Why is rhamnolipid production simply not 'on' at all times? This may be due to the fact that rhamnolipidinduced necrosis is not limited to PMNs or macrophages 
but affects all eukaryotic cells surrounded by a plasma membrane. We propose that too much rhamnolipid may cause inflammation and host tissue damage to levels beyond those favourable for the persistence of $P$. aeruginosa and therefore a tight regulation must take place at all times. Furthermore, the QS signals 3-oxo-C12 HSL and PQS have been reported to change the maturation pattern of stimulated dendritic cells away from a proinflammatory T-helper type I directing response, thereby decreasing the antibacterial activity of the adaptive immune defence (Skindersoe et al., 2009). The present study supports a model by which cross-kingdom-based communication contributes significantly to immunomodulation and evasion that facilitate the infective properties of $P$. aeruginosa.

This model suggests the potential for harnessing the power of small molecules that block bacterial QS systems as future antimicrobial medicines. A comparison with data from Hentzer et al. (2003) showed that $77 \%$ of the genes induced by exposure to PMNs can be significantly repressed by the QS blocker furanone C-30. This experimental drug is capable of blocking the aggressive anti-PMN response. Consequently, it restores the proper action of the attracted PMNs and strongly promotes bacterial clearance in animal models of infection (Christensen et al., 2007; Hentzer et al., 2003). Further study of interactions between $P$. aeruginosa and components of the innate and adaptive immune system will provide valuable information for the design of novel antimicrobials aimed at stimulating the efficiency of and restoring an adequate host defence.

\section{ACKNOWLEDGEMENTS}

This work was supported by grants from the Danish Research Council for Technique and Production (FTP) and the German Mukoviscidose ev to M.G. T.B. has received financial support from the Carlsberg Foundation and Lundbeck Foundation 'The implication of bacterial biofilms in chronic infections'. The authors would like to thank AdvanDx Inc., Woburn, MA, USA, for supplying the PNA probes for the PNA FISH visualization. Also, the authors thank Paul Williams and Steve Diggle for generously sharing the PAO1 pqs mutants. Collection of patient samples was done with the agreement of the patients and in accordance with the biomedical projects protocol (KA-20051011 and KF-01278432), both held by Thomas Bjarnsholt, and approved by the Danish Scientific Ethical Board.

\section{REFERENCES}

Aaron, S. D., Ferris, W., Ramotar, K., Vandemheen, K., Chan, F. \& Saginur, R. (2002). Single and combination antibiotic susceptibilities of planktonic, adherent, and biofilm-grown Pseudomonas aeruginosa isolates cultured from sputa of adults with cystic fibrosis. J Clin Microbiol 40, 4172-4179.

Aendekerk, S., Diggle, S. P., Song, Z., Høiby, N., Cornelis, P., Williams, P. \& Camara, M. (2005). The MexGHI-OpmD multidrug efflux pump controls growth, antibiotic susceptibility and virulence in Pseudomonas aeruginosa via 4-quinolone-dependent cell-to-cell communication. Microbiology 151, 1113-1125.
Allen, L., Dockrell, D. H., Pattery, T., Lee, D. G., Cornelis, P., Hellewell, P. G. \& Whyte, M. K. (2005). Pyocyanin production by Pseudomonas aeruginosa induces neutrophil apoptosis and impairs neutrophil-mediated host defenses in vivo. J Immunol 174, 36433649.

Bjarnsholt, T., Jensen, P. Ø., Burmolle, M., Hentzer, M., Haagensen, J. A., Hougen, H. P., Calum, H., Madsen, K. G., Moser, C. \& other authors (2005). Pseudomonas aeruginosa tolerance to tobramycin, hydrogen peroxide and polymorphonuclear leukocytes is quorumsensing dependent. Microbiology 151, 373-383.

Bjarnsholt, T., Kirketerp-Moller, K., Jensen, P. Ø., Madsen, K. G., Phipps, R., Krogfelt, K., Høiby, N. \& Givskov, M. (2008). Why chronic wounds will not heal: a novel hypothesis. Wound Repair Regen 16, 2-10.

Bortolussi, R., Vandenbroucke-Grauls, C. M., van Asbeck, B. S. \& Verhoef, J. (1987). Relationship of bacterial growth phase to killing of Listeria monocytogenes by oxidative agents generated by neutrophils and enzyme systems. Infect Immun 55, 3197-3203.

Brint, J. M. \& Ohman, D. E. (1995). Synthesis of multiple exoproducts in Pseudomonas aeruginosa is under the control of RhlR-RhlI, another set of regulators in strain PAO1 with homology to the autoinducerresponsive LuxR-LuxI family. J Bacteriol 177, 7155-7163.

Cabot, P. J., Carter, L., Schafer, M. \& Stein, C. (2001). Methionineenkephalin-and Dynorphin A-release from immune cells and control of inflammatory pain. Pain 93, 207-212.

Chadzinska, M., Starowicz, K., Scislowska-Czarnecka, A., Bilecki, W., Pierzchala-Koziec, K., Przewlocki, R., Przewlocka, B. \& Plytycz, B. (2005). Morphine-induced changes in the activity of proopiomelanocortin and prodynorphin systems in zymosan-induced peritonitis in mice. Immunol Lett 101, 185-192.

Chang, W., Small, D. A., Toghrol, F. \& Bentley, W. E. (2005). Microarray analysis of Pseudomonas aeruginosa reveals induction of pyocin genes in response to hydrogen peroxide. BMC Genomics $\mathbf{6}$, 115.

Christensen, L. D., Moser, C., Jensen, P. Ø., Rasmussen, T. B., Christophersen, L., Kjelleberg, S., Kumar, N., Høiby, N., Givskov, M. \& Bjarnsholt, T. (2007). Impact of Pseudomonas aeruginosa quorum sensing on biofilm persistence in an in vivo intraperitoneal foreignbody infection model. Microbiology 153, 2312-2320.

Clark, D. J. \& Maaløe, O. (1967). DNA replication and division cycle in Escherichia coli. J Mol Biol 23, 99-112.

Diggle, S. P., Winzer, K., Chhabra, S. R., Worrall, K. E., Camara, M. \& Williams, P. (2003). The Pseudomonas aeruginosa quinolone signal molecule overcomes the cell density-dependency of the quorum sensing hierarchy, regulates $r h l$-dependent genes at the onset of stationary phase and can be produced in the absence of LasR. Mol Microbiol 50, 29-43.

Donlan, R. M. \& Costerton, J. W. (2002). Biofilms: survival mechanisms of clinically relevant microorganisms. Clin Microbiol Rev 15, 167-193.

Fuqua, W. C., Winans, S. C. \& Greenberg, E. P. (1994). Quorum sensing in bacteria: the LuxR-LuxI family of cell density-responsive transcriptional regulators. J Bacteriol 176, 269-275.

Hentzer, M., Eberl, L., Nielsen, J. \& Givskov, M. (2003). Quorum sensing: a novel target for the treatment of biofilm infections. BioDrugs 17, 241-250.

Hentzer, M., Eberl, L. \& Givskov, M. (2005). Transcriptome analysis of Pseudomonas aeruginosa biofilm development: anaerobic respiration and iron limitation. Biofilms 2, 37-61.

Høiby, N. (1974). Epidemiological investigations of the respiratory tract bacteriology in patients with cystic fibrosis. Acta Pathol Microbiol Scand B Microbiol Immunol 82, 541-550. 
James, G. A., Swogger, E., Wolcott, R., Pulcini, E., Secor, P., Sestrich, J., Costerton, J. W. \& Stewart, P. S. (2008). Biofilms in chronic wounds. Wound Repair Regen 16, 37-44.

Jensen, P. Ø., Bjarnsholt, T., Phipps, R., Rasmussen, T. B., Calum, H., Christoffersen, L., Moser, C., Williams, P., Pressler, T. \& other authors (2007). Rapid necrotic killing of polymorphonuclear leukocytes is caused by quorum-sensing-controlled production of rhamnolipid by Pseudomonas aeruginosa. Microbiology 153, 1329-1338.

Jesaitis, A. J., Franklin, M. J., Berglund, D., Sasaki, M., Lord, C. I., Bleazard, J. B., Duffy, J. E., Beyenal, H. \& Lewandowski, Z. (2003). Compromised host defense on Pseudomonas aeruginosa biofilms: characterization of neutrophil and biofilm interactions. J Immunol 171, 4329-4339.

Kharazmi, A. (1991). Mechanisms involved in the evasion of the host defence by Pseudomonas aeruginosa. Immunol Lett 30, 201-205.

Kharazmi, A., Doring, G., Høiby, N. \& Valerius, N. H. (1984a). Interaction of Pseudomonas aeruginosa alkaline protease and elastase with human polymorphonuclear leukocytes in vitro. Infect Immun 43, 161-165.

Kharazmi, A., Høiby, N., Doring, G. \& Valerius, N. H. (1984b). Pseudomonas aeruginosa exoproteases inhibit human neutrophil chemiluminescence. Infect Immun 44, 587-591.

Kownatzki, R., Tummler, B. \& Doring, G. (1987). Rhamnolipid of Pseudomonas aeruginosa in sputum of cystic fibrosis patients. Lancet 1, 1026-1027.

Mah, T. F., Pitts, B., Pellock, B., Walker, G. C., Stewart, P. S. \& O'Toole, G. A. (2003). A genetic basis for Pseudomonas aeruginosa biofilm antibiotic resistance. Nature 426, 306-310.

Morici, L. A., Carterson, A. J., Wagner, V. E., Frisk, A., Schurr, J. R., Höner zu Bentrup, K., Hassett, D. J., Iglewski, B. H., Sauer, K. \& Schurr, M. J. (2007). Pseudomonas aeruginosa AlgR represses the Rhl quorum-sensing system in a biofilm-specific manner. J Bacteriol 189, 7752-7764.

Pamp, S. J. \& Tolker-Nielsen, T. (2007). Multiple roles of biosurfactants in structural biofilm development by Pseudomonas aeruginosa. J Bacteriol 189, 2531-2539.

Pedersen, S. S., Shand, G. H., Hansen, B. L. \& Hansen, G. N. (1990). Induction of experimental chronic Pseudomonas aeruginosa lung infection with $P$. aeruginosa entrapped in alginate microspheres. APMIS 98, 203-211.

Pfaffl, M. W. (2001). A new mathematical model for relative quantification in real-time RT-PCR. Nucleic Acids Res 29, e45.

Przewlocki, R., Hassan, A. H., Lason, W., Epplen, C., Herz, A. \& Stein, C. (1992). Gene expression and localization of opioid peptides in immune cells of inflamed tissue: functional role in antinociception. Neuroscience 48, 491-500.

Rasmussen, T. B., Skindersø, M. E., Bjarnsholt, T., Phipps, R. K., Christensen, K. B., Jensen, P. O., Andersen, J. B., Koch, B., Larsen,
T. O. \& other authors (2005). Identity and effects of quorum-sensing inhibitors produced by Penicillium species. Microbiology 151, 13251340.

Savli, H., Karadenizli, A., Kolayli, F., Gundes, S., Ozbek, U. \& Vahaboglu, H. (2003). Expression stability of six housekeeping genes: a proposal for resistance gene quantification studies of Pseudomonas aeruginosa by real-time quantitative RT-PCR. J Med Microbiol 52, 403-408.

Saye, D. E. (2007). Recurring and antimicrobial-resistant infections: considering the potential role of biofilms in clinical practice. Ostomy Wound Manage 53, 46-48, 50, 52.

Skindersoe, M. E., Zeuthen, L. H., Brix, S., Fink, L. N., Lazenby, J., Whittall, C., Williams, P., Diggle, S. P., Froekiaer, H. \& other authors (2009). Pseudomonas aeruginosa quorum-sensing signal molecules interfere with dendritic cell-induced T-cell proliferation. FEMS Immunol Med Microbiol 55, 335-345.

Small, D. A., Chang, W., Toghrol, F. \& Bentley, W. E. (2007). Comparative global transcription analysis of sodium hypochlorite, peracetic acid, and hydrogen peroxide on Pseudomonas aeruginosa. Appl Microbiol Biotechnol 76, 1093-1105.

Sonawane, A., Jyot, J. \& Ramphal, R. (2006). Pseudomonas aeruginosa LecB is involved in pilus biogenesis and protease IV activity but not in adhesion to respiratory mucins. Infect Immun 74, 7035-7039.

Stender, H. (2003). PNA FISH: an intelligent stain for rapid diagnosis of infectious diseases. Expert Rev Mol Diagn 3, 649-655.

Stewart, P. S. \& Costerton, J. W. (2001). Antibiotic resistance of bacteria in biofilms. Lancet 358, 135-138.

Wade, D. S., Calfee, M. W., Rocha, E. R., Ling, E. A., Engstrom, E., Coleman, J. P. \& Pesci, E. C. (2005). Regulation of Pseudomonas quinolone signal synthesis in Pseudomonas aeruginosa. J Bacteriol 187, 4372-4380.

Weyermann, J., Lochmann, D. \& Zimmer, A. (2005). A practical note on the use of cytotoxicity assays. Int J Pharm 288, 369-376.

Wu, H., Song, Z., Hentzer, M., Andersen, J. B., Heydorn, A., Mathee, K., Moser, C., Eberl, L., Molin, S. \& other authors (2000). Detection of $N$ acylhomoserine lactones in lung tissues of mice infected with Pseudomonas aeruginosa. Microbiology 146, 2481-2493.

Yang, L., Haagensen, J. A., Jelsbak, L., Johansen, H. K., Sternberg, C., Høiby, N. \& Molin, S. (2008). In situ growth rates and biofilm development of Pseudomonas aeruginosa populations in chronic lung infections. J Bacteriol 190, 2767-2776.

Zaborina, O., Lepine, F., Xiao, G., Valuckaite, V., Chen, Y., Li, T., Ciancio, M., Zaborin, A., Petrof, E. O. \& other authors (2007). Dynorphin activates quorum sensing quinolone signaling in Pseudomonas aeruginosa. PLoS Pathog 3, e35.

Edited by: P. Cornelis 